\title{
Corrigendum: Browsing Different Instagram Profiles and Associations With Psychological Well-Being
}

\author{
Kaitlyn Burnell ${ }^{1 *}$, Madeleine J. George ${ }^{2}$ and Marion K. Underwood ${ }^{3}$ \\ ${ }^{1}$ Department of Psychology and Neuroscience, Duke University, Durham, NC, United States, ${ }^{2}$ Purdue University, \\ West Lafayette, IN, United States, ${ }^{3}$ College of Health and Human Sciences, Purdue University, West Lafayette, IN, \\ United States
}

Keywords: Instagram, social media, feedback seeking, fear of missing out, well-being

\section{A Corrigendum on}

Browsing Different Instagram Profiles and Associations With Psychological Well-Being by Burnell, K., George, M. J., and Underwood, M. K. (2020). Front. Hum. Dyn. 2:585518. doi: $10.3389 /$ fhumd.2020.585518

\section{OPEN ACCESS}

Edited and reviewed by: Yalda Uhls,

University of California, Los Angeles, United States

*Correspondence: Kaitlyn Burnell kaitlyn.burnel/@duke.edu

Specialty section: This article was submitted to Digital Impacts, a section of the journal

Frontiers in Human Dynamics

Received: 02 March 2021 Accepted: 10 March 2021

Published: 08 April 2021

Citation:

Burnell K, George MJ and Underwood MK (2021) Corrigendum: Browsing Different Instagram Profiles and Associations With Psychological

Well-Being.

Front. Hum. Dyn. 3:675145 doi: 10.3389/fhumd.2021.675145
In the original article, there was an error. The regression mean square values were incorrectly labeled as the mean square error values.

A correction has been made to the "Effects of Condition on Post-browsing Reports" section.

To examine how post-browsing reports of affect and self-perceptions differed between conditions, a series of ANCOVAs were run (Figure 1). All analyses were run controlling for the corresponding pre-browsing assessment of each variable; marginal means are reported in-text and in Figure 1. Post-browsing self-esteem significantly differed by condition, $F_{(2,399)}=22.60$, $p<0.001, M S E=0.85, \eta_{\mathrm{p}}^{2}=0.10$. Participants in the self condition reported higher self-esteem $(M=5.88, S E=0.08)$ than those in the acquaintance $(M=5.30, S E=0.08)$ and influencer $(M=5.17, S E=0.08)$ conditions; the acquaintance and influencer conditions did not differ from each other $(p=0.277)$. Post-browsing positive affect significantly differed by condition, $F_{(2,400)}=8.19, p<0.001, M S E=0.90, \eta_{\mathrm{p}}^{2}=0.04$. Participants in the self condition reported higher positive affect $(M=4.49, S E=0.08)$ than those in the acquaintance $(M=4.17, S E$ $=0.08)$ and influencer $(M=4.04, S E=0.08)$ conditions; the acquaintance and influencer conditions did not differ from each other $(p=0.263)$. Post-browsing negative affect did not significantly differ by condition, $F_{(2,400)}=0.53, p=0.588, M S E=0.38, \eta_{\mathrm{p}}^{2}=0.00$. Post-browsing interpersonal negativity significantly differed by condition, $F_{(2,320)}=28.65, p<0.001, M S E=$ $1.33, \eta_{\mathrm{p}}^{2}=0.15$. Participants in the self condition $(M=1.32, S E=0.11)$ reported lower interpersonal negativity than those in the acquaintance $(M=2.14, S E=0.11)$ and influencer $(M=2.46, S E=0.11)$ conditions; the acquaintance and influencer conditions also significantly differed from each other $(p=0.045)$. Post-browsing positive self-perceptions significantly differed by condition, $F_{(2,400)}=23.42, p<0.001, M S E=0.56, \eta_{\mathrm{p}}^{2}=0.11$. Participants in the self condition reported greater positive self-perceptions $(M=4.72, S E=0.06)$ than those in the acquaintance $(M=4.20, S E=0.06)$ and influencer $(M=4.15, S E=0.07)$ 
conditions; the acquaintance and influencer conditions did not significantly differ from each other $(p=0.616)$.

The authors apologize for this error and state that this does not change the scientific conclusions of the article in any way. The original article has been updated.
Copyright $\odot 2021$ Burnell, George and Underwood. This is an open-access article distributed under the terms of the Creative Commons Attribution License (CC BY).

The use, distribution or reproduction in other forums is permitted, provided the original author(s) and the copyright owner(s) are credited and that the original publication in this journal is cited, in accordance with accepted academic practice. No use, distribution or reproduction is permitted which does not comply with these terms. 